\title{
PUBLICAÇÃO CONTÍNUA: NOVA MODALIDADE PUBLICAÇÃO DA REVISTA UNINGÁ REVIEW
}

\author{
CONTINUOS PUBLICATION: NEW PUBLISHING MODALITY OF UNINGÁ \\ REVIEW JOURNAL
}

\author{
Isaac Romani ${ }^{*}$ \\ ${ }^{1}$ Editor Chefe da Editora UNINGÁ.
}

*Rodovia PR - 317, n. 6114, Parque Industrial, Maringá / PR. CEP: 87035-510. E-mail: editora.uninga@uninga.edu.br

A Revista UNINGÁ Review iniciou, no ano de 2020, a divulgação de artigos científicos, no formato de publicação contínua - PC (Rolling pass). Neste formato de publicação, o artigo aceito e editorado, não é "arquivado" temporariamente até o momento da publicação trimestral (periodicidade anterior da Revista UNINGÁ Review).

Este é um grande passo da Revista UNINGÁ Review no sistema de publicação científica, juntando-se a outros journals ou plataformas de acesso aberto que usam este modelo a mais de 20 anos (Plos One e Scientific Reports). No Brasil, a PC é indicada pela coleção SciELO deste o ano de 2015.

Na publicação contínua, assim que o artigo é submetido pelas fases do fluxo editorial (avaliação duplo-cega, editoração, diagramação) e aprovado, ele é imediatamente publicado. Este procedimento aumenta a visibilidade dos artigos, ganhando maior impacto na consulta e citação destes artigos (RODRIGUES; SANTOS, 2019)

[...] a possibilidade inovadora da publicação contínua de artigos sem a necessidade de esperar a composição completa dos fascículos ou de edições seriadas. Essa modalidade promove rapidez no processo de comunicação e disponibilização das pesquisas com inúmeras vantagens para os usuários de informação científica: pesquisadores, estudantes, leitores, editores e agências de financiamento (SciELO, 2018)

De acordo com Campos (2018) este modelo possibilita aos autores maior agilidade na publicação dos seus trabalhos e a possibilidade da comunidade em acompanhar a descobertas científicas. As vantagens operacionais que tornam a PC recomendada pelo SciELO, segundo Parker et al. (2016) são: rápida e definitiva comunicação dos resultados de pesquisas; indexação dos artigos às bases de dados bibliográficas onde o periódico é indexado; redução do acúmulo de artigos já aprovados; manutenção da estrutura tradicional de volume / número e possibilidade de se ter vários números simultaneamente (seções ou números temáticos).

Uma vez que a publicação de novos artigos pode ser realizada com maior agilidade, a distribuição de informes com os artigos mais recentemente publicados se apresenta mais constante, o que contribui para incrementar a visibilidade do periódico e, assim, sua recepção pelos potenciais leitores (PRIETO; PIETRI, 2018). Este novo sistema de publicação alia-se à Ciência 
Aberta, importante tendência na comunicação da pesquisa científica, cujo objetivo é contribuir com a pesquisa colaborativa e possibilitar o acesso ao conhecimento científico.

Essa inovação não irá alterar a disposição dos artigos publicados nas três seções já existentes: Meio Ambiente e Agrárias; Ciências Exatas, da Terra e Engenharia; Ciências Sociais e Humanas da Revista UNINGÁ Review. Mudanças serão visíveis apenas na paginação, assim, todos os artigos perdem a informação de paginação contínua e sequencial e atribui-se o identificador eletrônico chamado de elocation-id, único dentro do fascículo (SciELO 2018).

O fluxo editorial segue normalmente. Os autores após realizarem 0 cadastro no site da revista (http://revista.uninga.br/index.php/uningareviews), realizam a inclusão dos metadados, anexam o manuscrito e submetem. 0 gerenciamento do fluxo editorial é realizado via Open Journal System - OJS (desk review, avaliação duplo-cega, editoração e diagramação) até a sua publicação.

E com grande satisfação que informamos a comunidade científica esta nova modalidade de publicação, almejando contribuir com a disseminação do conhecimento científico e fortalecimento da Revista UNINGÁ Review. Da mesma forma, reiteramos o convite a todos os autores, para publicarem seus manuscritos em nossa revista.

\section{REFERÊNCIAS}

CAMPO, F. P. F. Continuous publication: changing the publishing model. Autopsy Case Reports, v.8, n.1, e2018017, 2018. Disponível em: https://www.researchgate.net/publication/323821485_Continuous_Publication_ Changing_the_publishing_model. Acesso em: 29 jun. 2020.

PRIETO, R. G.; PIETRI, E. Desafios e possibilidades da publicação contínua para o trabalho dos editores de periódicos científicos. Educação e Pesquisa. Editorial, v. 44, 2018. Disponível em: https://www.scielo.br/scielo.php?script=sci_ arttext\&pid=S1517-97022018000100100. Acesso em: 29 jun. 2020

PACKER, A., et al. Acelerando a comunicação das pesquisas: as ações do SciElO [online]. SciElO em Perspectiva, 2016. Disponível em: https://blog.scielo.org/blog/2016/03/10/acelerando-a-comunicacao-daspesquisas-as-acoes-do-scielo/. Acesso em: 29 jun. 2020.

RODRIGEUS, C. M.; SANTOS, G. C. A importância e o impacto da Publicação Contínua (PC) nos periódicos Eletrônicos. Blog PPEC, Campinas, v. 1, n.1, jan. 2019. ISSN 2526-9429. Disponível em: http://periodicos.sbu.unicamp.br/blog/index.php/2019/01/15/pc/. Acesso em: 29 jun. 2020.

SciELO. Guia para publicação contínua de artigos em periódicos indexados no SciELO. 2018. Disponível em: http://www.scielo.org/local//mage/guiarpass. pdf. Acesso em: 29 jun. 2020. 